\title{
El Marxismo de Walter Benjamin
}

\author{
Walter Benjamin's Marxism
}

Aureliano Ortega Esquivel Universidad de Guanajuato - México Guanajuato, México

aure_liano@hotmail.com

\section{RESUMEN}

En el presente artículo se examinan y exponen los usos de las nociones de dialéctica, materialismo y revolución en algunos pasajes de las obras de Walter Benjamin. Como resultado, se concluye que el pensamiento del autor alemán es, como han sostenido algunos de sus lectores más atentos, una original y potente amalgama de pensamiento crítico en la que concurren elementos del marxismo, el romanticismo, el surrealismo y la mística judía en su versión mesiánica, lo que, lejos de resultar un despropósito, le permite develar y revelar los pliegues, las grietas, los defectos y los aspectos menos reconocidos del desarrollo de la Modernidad y la Modernidad capitalista, tanto a lo largo del siglo XIX como en la configuración social y cultural que le tocó vivir durante el primer tercio del siglo XX; atravesada ésta por contradicciones de toda índole entre las que se perpetúan y aun consolidan el sufrimiento, la violencia y la marginalidad de los desposeídos. Como se desprende de sus intervenciones, desde muy joven, Benjamin trazó una agenda crítica en la que figuran problemas relativos al lenguaje, la violencia, el derecho, el arte y el pensamiento crítico. Es en la tentativa de recuperar y caracterizar los elementos comunes a todas esas figuras que Benjamin se encuentra con la dialéctica como una herramienta teórico-crítica cuya potencia se verá manifiestamente incrementada con la adopción y reformulación del materialismo histórico como el método apropiado para desmontar, entender y eventualmente transformar el mundo mediante la revolución.

Palabras clave: Walter Benjamin, crítica, dialéctica, materialismo histórico, revolución.

\section{ABSTRACT}

This essay examines and exposes the uses of the notions of dialectic, materialism and revolution in some passages of the works of Walter Benjamin. As a result, it is concluded that the thought of the Berlin author is, as some of his most attentive readers have argued, an original and powerful amalgam of critical thought in which elements of Marxism, Romanticism, Surrealism and Jewish mysticism concur in his messianic version, which, far from being nonsense, allows it to unveil and reveal the folds, cracks, defects and less recognized aspects of the development of Modernity and Capitalist Modernity, both throughout the 19th century and in the social-cultural configuration that he had to live during the first third of the 2oth century; crossed by contradictions of all kinds between which the suffering, violence and marginalization of the dispossessed are perpetuated and even consolidated. As can be seen from his interventions, from a very young age, Benjamin drew up a critical agenda that included problems related to language, violence, law, art and critical thinking. It is in the attempt to recover and characterize the elements common to all these figures that Benjamin comes across dialectics as a theoretical-critical tool whose power will be manifestly increased with the adoption and reformulation of historical materialism as the appropriate method to dismantle, understand and eventually transform the world through revolution.

Keywords: Walter Benjamin, criticism, dialectic, historical materialism, revolution. 


\section{INTRODUCCIÓN}

No es habitual incluir a Walter Benjamin entre los pensadores más destacados del llamado Marxismo occidental, aun cuando existe, desde mediados de los años setenta del siglo pasado, una importante corriente de pensamiento crítico (Buck-Morse, 1981; Buck-Morse, 1995; Löwy, 2001 y Forster, R. 2014), que no solamente apuesta a la recuperación de ideas y textos en los que el pensador berlinés se identifica abiertamente con una versión, ciertamente propia y peculiar, del “materialismo histórico", sino en razón de que, a pesar de portar destacables elementos de la mística judía, de la tradición romántica, del psicoanálisis y del surrealismo, su pensamiento crítico, justo por ser un ejemplar "poco corriente" al interior de la tradición marxista, ha conservado hasta nuestros días la frescura y el agudo filo crítico que — provenientes de la "inconstancia latina" que Karl Korsch atribuía al pensamiento de Marx-, le han permitido sortear, sin perder un ápice de su profundidad y pertinencia, no sólo el desencanto posmoderno y la tentativa de "secuestro" que la derecha llevó a cabo a través de su asimilación a la "critica erudita de la Modernidad", sino a la desbandada general que provocó entre los marxistas académicos la caída del Socialismo real (Eagleton, 1998).

En los apuntes que esbozamos a continuación, a través del examen de tres enclaves teóricos: la dialéctica, el materialismo histórico y la revolución, se propone una interpretación del pensamiento de Walter Benjamin que lo sitúa, sin mayor escándalo, al interior de la tradición del Marxismo occidental, sin dejar de considerar que se trata, por una parte, de un marxismo que no requiere invocar el nombre de Marx a cada paso y que, inclusive, llega a ser agudamente crítico con el autor de El Capital; y, de otra, que parte de la certeza de que en la actualidad la "ortodoxia" es un mito, y que el momento por el que atraviesa la humanidad, el que puede ser asumido sin cortapisa alguna como crisis civilizatoria, todavía requiere de los irrenunciables servicios de la crítica, y, como parte de ella, de todo pensamiento que, como lo hizo Benjamin en su momento, la oriente hacia el mundo de la belleza y de la no violencia.

\section{HISTORIA Y DIALÉCTICA}

\section{El desarrollo estatal alemán era por sí mismo} una tragedia. (Walter Muschg)

El texto que lleva por nombre "Prólogo epistemocrítico" fue concebido por Walter Benjamin como introducción al trabajo El origen del 'Trauerspiel' alemán, una obra escrita en 1925 - cuando ya Benjamin estudiaba intensamente el pensamiento marxista-, pero finalmente publicada hasta 1928. Como se sabe, dicha obra, incluido este Prólogo, fue propuesto por Benjamin a la Universidad de Frankfurt con la pretensión de obtener la habilitación como Privatdozent en filosofía y literatura, intento, ciertamente temerario, que fracasó ante la pequeñez filosófica de la burocracia universitaria. Sobre el contexto en el que la obra fue concebida y escrita se ha hecho canónica la opinión de Gershom Scholem, en el sentido de que el fondo filosófico y las ideas que lo sostiene no salen del ámbito teológico-metafísico en el que se movía Benjamin en esos años y que, en el mejor de los casos, las dos aguas en las que filosóficamente se trataba de mantener a flote - quien inclusive había pensado ingresar en el Partido Comunista Alemán- ya entrechocaban o se yuxtaponían en sus cartas y conversaciones, pero no se plasmaron en el texto mismo; lo que permite escribir a Scholem:

El conflicto entre sus modos metafísicos de pensar y los marxistas, en los que trataba de transformar aquellos, comenzó a determinar su vida espiritual desde 1929 en adelante, marcándola de una manera absolutamente inconfundible (...) El libro sobre el Trauerspiel, en cuyo período de incubación la perspectiva comunista no se hizo valer sino como un elemento retardatario, no contiene la menor referencia ni el concurso de tales ideas. El trasfondo filosófico que confirió al libro, así como los temas en él desarrollados sobre la dialéctica del fenómeno del "Trauerspiel”, permanecen en el ámbito metafísico del que provienen y al que se mantienen encadenados incluso en su ejecución. No hay vestigio de categoría marxista alguna. (1987, p. 131) 
Las notas que ahora se presentan no pretenden ser solamente una réplica a la opinión de Scholem -la que, por cierto, al confundir la "perspectiva comunista" con las "ideas marxistas" hace derivar sus (pre) juicios hacia una reprobación sumaria ("elemento retardatario") que tiene mucho de retórico-, sino mostrar cómo la dialéctica benjaminiana no sólo nos sorprende a cada paso con desenlaces inesperados, sino que, en el ámbito del pensamiento crítico puede inclusive desafiar el orden histórico; o, si se quiere, y para no dejar de lado el ámbito de nuestro asunto, puede poseer la virtud de no hacer llegar las cosas "hasta 1929" sino asaltar por la espalda al buen metafísico berlinés e inmiscuirse solapadamente en sus textos idesde 1925! Pero no se trata de arrojar más leña metafísica al fuego en el que Scholem querría haber quemado el marxismo-comunismo de su inconstante amigo, sino mostrar que el pensamiento dialéctico, aun enderezado hacia la crítica de un fenómeno literario menor, conserva, por una parte, la potencia de llevar las cosas hacia lo inmanente, y, por lo tanto, hacia el horizonte de la "vida material" y de su crítica; y, por otra, aun es capaz de encaminar la búsqueda de la verdad hacia el insustituible plano comprensivo de la historia. Con lo que tenemos como resultado que aun aceptando que se haya escrito "sin vestigio de categoría marxista alguna", el Prólogo, estructurado a partir de un innegable acento dialéctico, puede ser leído críticamente como un documento emblemático del tipo de materialismo histórico que se forjaba en esos años y que tiene en el connotados marxista Georg Lukács a uno de sus representantes máximos.' Pero como no es el caso inventar nada, sino rastrear detrás de esa aparente ausencia de "vestigios de categorías marxistas" las intrincadas sendas de leñadores por las que a veces transita el marxismo poco corriente, es preciso emplazar las cosas sobre bases cuya improbable estabilidad depende de la proverbial inquietud de los conceptos utilizados en la empresa.

La intención final del libro de Benjamin es la de mostrar cómo, por qué vías expresivas cobra forma, con qué herramientas discursivas cuenta y hacia qué desenlaces literarios y culturales derivó el drama barroco alemán entre los siglos XVII y XVIII. Género literario y escénico considerado generalmente "menor", en los libros de texto se sitúa a medio camino entre el gran drama Isabelino (Shakespeare, Marlowe) y la tragedia clásica alemana (Goethe, Schiller) (Muschg, 1965, p. 395), pero al que en su momento no faltaron autores de talento y un público enterado e indulgente. En ese sentido, el libro desarrolla un ejercicio de análisis erudito que puede leerse como otra contribución a la historia y la crítica de la literatura alemana. Sin embargo, siendo Benjamin su autor, tal contribución podía ser todo: menos edificante. Y no precisamente porque en el plano comparativo los dramaturgos españoles, especialmente Calderón, resultasen "mejores" escritores que Gryphius o Lohenstein, sino en virtud de que lo mostrado finalmente por el autor berlinés no son sólo las limitaciones literarias de los dramaturgos alemanes del barroco, sino las miserias culturales y sociales de los reinos y principados del archipiélago político alemán; asunto que tal vez esté en la base del enfado de sus lectores-sinodales de la Universidad de Frankfurt. Pero el asunto aquí no es ni el drama barroco, ni las universidades alemanas de principios del siglo XX, sino un fragmento de discurso en el que sospechamos cualidades críticas que merecen el apelativo de dialécticas, materialistas e históricas; para dejar a Marx y el nombre del marxismo en paz, aunque sea por el momento.

El Prólogo se compone de quince parágrafos en los que se despliegan y entrelazan temas relativos al "método correcto" para abordar el estudio del Trauerspiel: mismo que se sitúa desde el primer momento en la filosofía y no en la crítica literaria. Pero la filosofía, de acuerdo con Benjamin, es problemática, es decir, "no se puede conjurar more geométrico" sino en codificación histórica (Benjamin, 2007, p. 223). Sin embargo, aun encuadrada en esa perspectiva, puede seguir la vía franca y lineal de los "tratados" o la del golpe de vista con el que leemos el enigmático "mosaico". En todo caso lo que una y otra forma expositivas ponen sobre el tapete son "ideas"; ni datos ni hechos, sino lo que, a partir de datos y hechos, es decir, de "fragmentos", la filosofía pueda exponer; con lo que nos encontramos frente a una formulación netamente benjaminiana cuya expresión máxima solamente será expuesta en el rompecabezas titulado Libro de los Pasajes.

\footnotetext{
1 Véase a ese respecto el trabajo de Lukács "Metafísica de la tragedia", un ensayo de 1910 escrito desde un inequívoco emplazamiento metafísico propio de los estertores de la filosofía del Espíritu que, empero, es sorprendentemente hábil para mostrar el carácter histórico y dialéctico de la tragedia. Lukács, G. (1985)
} 
El valor de los fragmentos de pensamiento es tanto más decisivo cuanto menos se puedan medir inmediatamente por la concepción fundamental, y de él depende el brillo de la exposición en la misma medida en que depende el del mosaico de la calidad que tenga el esmalte. La relación del trabajo microscópico con la magnitud del todo plástico y del intelectual expresa cómo el contenido de verdad sólo se puede aprehender con la inmersión más precisa en los detalles de un contenido objetivo. En su suprema configuración occidental, mosaico y tratado pertenecen a la Edad Media; así, lo que posibilita su comparación es una auténtica afinidad. (Benjamin, 2007, p. 225)

Lo que aquí destaca es, de entrada, la necesidad dialéctica de la totalidad; la elección no es entre uno u otro extremo: tratado $o$ mosaico; son ambos, porque son "afines"; y son afines porque como efecto de su articulación muestran; y solamente porque logran hacerlo son los caminos que expresan la "pujanza" de la verdad. Porque ya se dijo, pero se repite: El objeto de la indagación que se propone "son las ideas" porque el Trauespiel debe recibir el trato no de un género, sino de una idea (Benjamin, 2007, p. 223), y las ideas, afirma Benjamin, no pueden tratarse adecuadamente ni como cosas ni como formas puras; pero tampoco solamente como conceptos. Mas, si las ideas no pueden tratarse aun como conceptos - porque éstos tienden a cristalizar un sentido que originariamente se niega al reposo o que no renuncia a la inquietud- ¿desde qué clase de horizonte epistémico el pensamiento será capaz de aprehenderlas-expresarlas adecuadamente?

Es tal vez el paseo por los meandros del pensamiento de Platón en la que discurre la primera parte del texto - junto con la afirmación enfática de que el objeto de esta indagación sobre el Trauerspiel es "las ideas" - lo que desconcierta a los lectores y quizá ha llevado a Scholem a la tozuda afirmación de que su amigo nada como pez en aguas metafísicas. Pero no es así; la Idea en Platón, no es la misma Idea en Benjamin. La primera reposa en el Topus Uranus en calidad de principio puro y arquetípico; la segunda se mueve a ras de tierra. La primera conserva incólume la condición de forma; la segunda es un "momento" en el proceso de su propia realización: "Pues las ideas no se exponen en sí mismas, sino única y exclusivamente en la ordenación de elementos cósicos que se da en el concepto. Y en cuanto configuración de dichos elementos es como lo hace ciertamente" (Benjamin, 2007, p. 230). De esta afirmación, que podría haber suscrito Hegel, se concluye que el "método correcto" para abordar la comprensión filosófica del Trauerspiel es aprehenderlo-expresarlo como "idea"; es decir: como realización de algo que no pierde su condición "cósica" aun enredado en la espesa trama de los conceptos: lo que viene a decir que no puede ser abordado estrictamente como literatura, sino como filosofía y como historia. Otra vez en Benjamin, como sucede en otros de sus artículos tempranos, a pesar de no ser "todavía marxista" y de proponer una trama aprehensiva-expresiva aparentemente metafísica, ésta se revela como dialéctica e histórica; en donde la inmanencia cósica aparece como clave de arco de la comprensión.

Sin embargo, existe otro tópico en el Prólogo que exhibe su innegable y definitiva afinidad con la dialéctica y el materialismo histórico: el concepto de “origen", ni más ni menos. Porque Benjamin no entiende por origen el conjunto de fuentes ni literarias ni contextuales de las que abreva el Trauerspiel como género; porque éste tampoco puede entenderse ni en su contexto ni en su evolución genética. En primer lugar porque, como se ha dicho, aquel no es un género literario sin más, sino una idea expresada en una "imagen dialéctica" que va más allá de los conceptos porque lo es de "algo" que no es él mismo, pero que forma parte de él y opera en su constitución esencial. Es, sí, una idea, pero una idea preñada de historia; por tercera ocasión aparece, aquí, la historia.

El origen, por tanto, no se pone de relieve en el dato fáctico, sino que concierne a su prehistoria y posthistoria. En cuanto a las directrices correspondientes a la consideración filosófica, se encuentran trazadas en la dialéctica inherente al origen. Y esta prueba como, en todo lo esencial, la unidad y la reciprocidad se condicionan. La de origen no es, por tanto, tal como cree Cohen, categoría puramente lógica, sino histórica. (Benjamin, 2007, p. 243)

Pero no cualquier historia, sino solamente aquella que aprehende el sentido del Trauespiel bajo la deter- 
minación de lo que más tarde Benjamin llamará "tiempo-del-ahora", en el que es posible captar la "prehistoria y poshistoria" del fenómeno, es decir, una aprehensión que anuncia ya una crítica a la idea de un tiempo homogéneo y vacío y que es capaz de ordenar los "elementos cósicos" que le subyacen a todo hecho en calidad de "origen" para expresarlos finalmente en la imagen de un tratado-mosaico capaz de hacer justicia a su inquietud. Pero tampoco se agota aquí la fuerza comprehensiva de la noción de origen, sino en cuanto se articula ceñidamente con su consideración dialéctica a través de la prueba de que "la unicidad y la reciprocidad" se condicionan.

Ha dicho Adorno que la filosofía es "su tiempo atrapado en pensamientos". Es posible pensar que, desde la perspectiva de su origen, el Trauerspiel es, para el presunto Benjamin metafísico "su tiempo atrapado en tramas dramáticas". Pero la lectura comprensiva de ese tiempo y de las tramas que lo "atrapan" no reclama una red ni de intuiciones puras ni de conceptos, sino un tratado-mosaico configurado con preguntas y respuestas sobre las formas específicas en las que los elementos cósicos que subyacen al Trauespiel se expresan, contemporáneamente, en términos de trama histórica y dramática.

Pues este, aunque categoría absolutamente histórica, no tiene nada que ver con la génesis. Porque en efecto, el origen no designa el devenir de lo nacido, sino lo que les nace al pasar y al devenir. El origen radica en el flujo del devenir como torbellino, engullendo en su rítmica el material de la génesis. Lo originario no se da a conocer nunca en la nuda existencia palmaria de lo fáctico, y su rítmica únicamente se revela a una doble intelección (...) En cada fenómeno de origen se determina la figura bajo la cual una idea no deja de enfrentarse al mundo histórico hasta que alcanza su plenitud en la totalidad de su historia (Benjamin, 2007, p. 243).

\section{HORA DE DESPERTAR A MARX}

3.1 Materialismo Histórico y revolución

Roturar terrenos en los que hasta ahora sólo crece la locura. (W. Benjamin).

En los numerosos, pero igualmente dispersos pasajes de la obra de Walter Benjamin en los que se refiere al "materialismo histórico", el enunciado alude básicamente a un método de conocimiento crítico. Un método que, no exento de tonos de excentricidad y mesianismo, recupera la posición de discurso esencial del pensamiento marxista, misma que, al referirse a los elementos cósicos propios de una formación social dada, subraya en primera, pero no en única instancia, la determinación histórica que la estructura económica mantiene sobre el conjunto de sus expresiones jurídicas, políticas, culturales y artísticas, y que, en consecuencia, afirma que no es la conciencia de los hombres la que determina su ser, sino, por el contrario, es su ser social el que determina su conciencia. Esta consideración nuclear, deformada hasta el extremo por el marxismo vulgar, obliga a Benjamin a precisar que su materialismo no es un horizonte de aprehensión-expresión cognoscitiva que se dirima en el espacio cerrado de la relación sujeto-objeto, de talante puramente epistemológico, sino algo que, de la mano de la crítica, aspira a ir más allá: “[...] separar la verdad de la falsedad es la meta de la metodología materialista, no su punto de partida. En otras palabras, su punto de partida es el objeto cargado de error, de doxa" (Eagleton, 1981, p. 46). El materialismo de dicha posición afirma así el carácter práctico-concreto de todo acto social-humano, porque no sólo parte de los elementos cósicos (el objeto cargado de error) en los que se anuda la existencia, sino se sustenta en la crítica a la que Marx somete las inconsecuencias y límites epistémicos que tanto el materialismo mecanicista de los pensadores del siglo XVIII como el materialismo antropológico del XIX no pueden rebasar, al concebir, ambos, la relación sujeto-objeto como actividad meramente empírico-contemplativa en la que el objeto se impone al sujeto como realidad externa y preexistente, como objeto de contemplación, o como doxa, cuyos sentido y sustancia son ajenos a toda relación hombre-naturaleza. A lo que Benjamin opone una teorización de la relación sujeto-objeto como proceso de transformación recíproca o "entramado causal” 
entre los hombres y su entorno natural y cultural, aunque con énfasis especial en su carácter expresivo.

\begin{abstract}
Marx expone el entramado causal entre la economía y la cultura. Aquí se trata del entramado expresivo. No se trata de exponer la génesis económica de la cultura, sino la expresión de la economía en su cultura. Se trata, en otras palabras, de intentar captar un proceso económico como visible fenómeno originario de donde proceden todas las manifestaciones de la vida de los pasajes (y con ello del siglo XIX). (Benjamin, 2005, p. 462)
\end{abstract}

Por su parte, el sentido histórico que complementa este materialismo que desde su formulación originaria aspira a la totalidad, alude al hecho de que toda relación sujeto-objeto, ya sea en el plano de conocimiento, en el plano de la vida material y, sobre todo, en el plano de su expresión, son eventos práctico-concretos que se desenvuelven en ese "entramado causal" históricamente determinado, en el que confluyen no solamente elementos de orden temporal; sino, sobre todo, elementos prácticos que suponen ciertas condiciones de desarrollo histórico de la vida material, social y cultural, pero que no se allanan unilateralmente a estas porque ellas mismas son, también, un resultado de sus propias formas expresivas.

Esta investigación [el Libro de los pasajes], que en el fondo tiene que ver con el carácter expresivo de los primeros productos industriales, de los primeros edificios industriales, de las primeras máquinas, pero también de los primeros grandes almacenes, anuncios publicitarios, etc., posee con ello una doble importancia para el marxismo. En primer lugar, encontrará de qué manera el mundo en el que surgió la doctrina de Marx influyó en ésta, no sólo mediante sus conexiones causales, sino mediante su carácter expresivo. Pero también mostrará, en segundo lugar, qué rasgos comparte igualmente el marxismo con el carácter expresivo de los productos materiales de su tiempo. (Benjamin, 2005, p. 462)

A esta definición, de por sí ajena ya a toda ortodoxia, a lo largo de varios trabajos y de manera harto dispersa, Benjamin sumará algunos otros elementos de orden teórico-metodológico — propios de la dialéctica, el romanticismo, el surrealismo y aun el psicoanálisis- que de alguna forma enriquecen y rubrican la originalidad de su versión primitiva, en tanto: a) procuran superar la rigidez que presenta la relación estructura-superestructura en su versión dogmática y mecánica; b) enfatizan la función comprensiva de la expresión; c) radicalizan el efecto crítico que de suyo la dialéctica y el materialismo ya portan a través de la dimensionalización de todo acto de orden histórico concreto en la perspectiva de la lucha de clases, de la resistencia contra el fascismo y en el camino de la revolución; d) proponen la técnica del montaje literario y cinematográfico como formato adecuado a la exposición de los resultados de sus investigaciones ${ }^{2}$, de manera muy problemática pero sorprendentemente consecuente; e) incorporan elementos de la mística judía como recurso crítico frente al talante positivo que afecta algunas versiones del materialismo histórico, lo que, de otro modo, comprometería su potencial crítico y revolucionario frente a las doctrinas positivista e historicista del progreso.

Se puede considerar como uno de los objetivos metódicos de este trabajo [el Libro de los Pasajes] mostrar claramente un materialismo histórico que ha aniquilado en su interior la idea de progreso. Precisamente aquí, el materialismo histórico tiene todos los motivos para separarse con nitidez de la forma burguesa de pensar. Su concepto principal no es el progreso, sino la actualización. (Benjamin, 2005, p. 463)

Uno de estos peculiares “usos” del materialismo histórico a los que apela Benjamin se encuentra en el tra-

\footnotetext{
2 "Método de este trabajo: montaje literario. No tengo nada que decir: Sólo que mostrar. No hurtaré nada valioso, ni me apropiaré de ninguna formulación profunda. Pero los harapos, los deshechos, esos no los quiero inventariar, sino dejarles alcanzar su derecho de la única manera posible: empleándolos" (Benjamin, 2005, p. 462).
} 
bajo El Surrealismo. Última instantánea de la inteligencia europea, publicado en 1929. Conservando siempre el carácter de ensayo o "tentativa" que presentan los desarrollos teóricos del filósofo berlinés, es posible reconocer en dicho trabajo el esfuerzo por incorporar a la definición nuclear de materialismo histórico. Formulaciones propias de la propuesta surrealista que no sólo reconocen el carácter revolucionario que de suyo porta una apuesta intelectual y política de tal naturaleza, sino aun agudizan el sentido crítico de aquella. En un listado no limitativo, se puede destacar como elementos en principio ajenos al materialismo histórico, pero introducidos por Benjamin "a contrapelo", la dialéctica sueño-vigilia, el sentido esclarecedor de la "iluminación profana" o el carácter político y transgresor del "pesimismo activo". ${ }^{3}$ Asimismo, en éste y en otros textos, en donde el sueño se asocia a la eficacia del mito (y el mito a la prehistoria, en sentido marxista, de la humanidad) el despertar significa disolver la mitología en el espacio de la historia (Benjamin, 2005, p. 460), pero no de la historia considerada en gran formato, sino la historia de lo cotidiano, de las cosas pequeñas en las que se han inscrito las vidas comunes y corrientes de sus poseedores y que, en su concreción sensible-profana, manifiestan el carácter de la totalidad social-cultural de la que formaron parte. (Tiedemann en Benjamin, 2005, p. 16-19)

Es importante rendir cuentas de la herencia directamente recibida. Pero aún es demasiado pronto, p. ej., para reunirla. Lo que hace falta es una reflexión concreta, materialista, sobre lo más cercano. La “mitología”, como dice Aragón, vuelve a alejar las cosas. Sólo es importante exponer lo que nos es afín, lo que nos condiciona. El siglo diecinueve, por hablar con los surrealistas: los ruidos que se mezclan con nuestros sueños son los que, al despertar, interpretamos. (Benjamin, 2005, p. 829)

Años más tarde, el artículo "Eduard Fuchs. Coleccionista e historiador" publicado en 1937, representa a todas luces una versión madura del materialismo histórico en cuyo marco, Benjamin se plantea la necesidad de una historia materialista del arte que, sin llegar a violentar la idea de la determinación de "la vida material" sobre la "conciencia" (y en este caso sobre el conjunto de sus expresiones superestructurales) pone en cuestión el aislamiento de los diversos ámbitos culturales y de sus figuras específicas para superar dos vicios propios del espacio intelectivo en el que hasta entonces se ha desarrollado la recuperación histórica de la expresión y la vida del espíritu: por una parte las Ciencias del Espíritu y, por otra, el "naturalismo" que propone el materialismo mecanicista de autores como Plejanov. Sobre el primer vicio, caracterizado como idealista, Benjamin, apoyado en Engels, critica tanto la historia de las ideas políticas, jurídicas y artísticas o culturales que de ordinario cultivan la Ciencias del Espíritu al margen de su base histórico-material, como, en sentido inverso, la ausencia en éstas de una reflexión consecuente sobre "el efecto que ellas [las ideas] causan sobre los seres humanos y sobre su proceso de producción, tanto espiritual como económico" (Benjamin, 2009, p. 67). Como respuesta al segundo vicio, nuestro autor, más allá de denunciar el mecanicismo que exhibe la consideración meramente naturalista de la expresión artística, amplifica el ángulo de visión, y se propone superar críticamente el materialismo mecanicista — cuyo fundamento se remite a las ciencias naturales-, justo en contra de su optimismo determinista y sucedáneo del naturalismo asociado a la doctrina del progreso, ya que, en los hechos, obstruye la posibilidad de entender el pasado como "catástrofe" y pone en entredicho la acción revolucionaria del proletariado (Benjamin, 2009, p. 91).

El materialista histórico adopta una actitud bien reservada frente a dicha historia cultural. Para justificar esta actitud, nos bastaría sólo con echar un vistazo al pasado: todo el arte y la ciencia que el materialista histórico perciba tiene procedencia que él no pueda contemplar con horror. Pues todo eso tiene su existencia no tan sólo en el esfuerzo de aquellos grandes genios que lo han ido creando, sino también (en grado menor o mayor) a la esclavitud anónima de sus contemporáneos. No hay ningún documento de cultura que no sea al tiempo un documento de barbarie. (Benjamin, 2009, p. 80).

Pero Benjamin no se detiene ahí, porque contemporáneamente, y en ese mismo plano crítico, en el artícu-

3 Ver: Löwy. M. (2020). 
lo sobre Fuchs es posible encontrar una importante inflexión sobre el carácter destructivo/negativo de la dialéctica, tanto como su inextricable articulación con la acción revolucionaria del proletariado:

Sin duda, exponer la historia cultural a partir de la base de la historia pragmática es un disparate. Pero más grave es el disparate de elaborar una historia cultural de corte dialéctico, dado que la supuesta continuidad de la historia, que ha saltado ahora por los aires gracias a la dialéctica, no padece en ningún lugar dispersión más intensa que en aquel que llamamos “cultura” [...] como tal, la historia cultural representa un avance del conocimiento tan sólo en apariencia, y ni siquiera en apariencia representa un avance para la dialéctica. Pues le falta el momento destructivo que garantiza la autenticidad del pensamiento dialéctico y de la experiencia del dialéctico. En efecto, la historia cultural incrementa la carga de los tesoros que se van acumulando en las espaldas de la humanidad, pero no le da a ésta la fuerza para sacudirse dicha carga y tomarla en sus manos. (Benjamin, 2009, p. 81). ${ }^{4}$

La suma de los elementos que confluyen en la construcción del materialismo histórico y del método crítico que se propone Benjamin se verifica paulatinamente a lo largo de muchos años y se asocian, principal pero no únicamente, al desarrollo del llamado Libro de los Pasajes (2005); un proyecto que se propone reescribir la historia de la modernidad a través del acopio, el examen y el montaje crítico-negativo de testimonios de orden artístico, literario, social y cultural que la historiografía burguesa siempre ha dejado de lado. En este inmenso borrador, tanto la expresión como algunas aplicaciones analíticas o metodológicas del materialismo histórico, ocupan un importante número de páginas y referencias, entre las que Benjamin propone cierta "doctrina elemental" del materialismo histórico que no sólo rubrica su alejamiento de toda ortodoxia, sino le imprime a la definición nuclear del materialismo histórico un sentido notablemente más profundo:

En torno a la doctrina elemental del materialismo histórico. 1) Objeto de la historia es aquello en lo que se realiza el conocimiento como su salvación. 2) la historia se descompone en imágenes, no en historias. 3) Allí en donde se lleva a cabo un proceso dialéctico, tenemos que habérnoslas con una mónada. 4) La exposición materialista de la historia conlleva una crítica inmanente al concepto de progreso. 5) El materialismo histórico apoya su proceder en la experiencia, en el sano sentido común, en la presencia de espíritu y en la dialéctica. (Benjamin, 2005, p. 478)

Encontramos aquí un conjunto de sentencias que ilustran lo que concierne al concepto de materialismo histórico de manera tendencialmente completa, aunque no hay que perder de vista el hecho de que cada una de ellas conserva un peso y un desarrollo desigual en el corpus benjaminiano. Los temas relativos a la salvación (redención), al progreso, a la "detención mesiánica del acaecer" y al rompimiento del continuum histórico que implican directamente la articulación del materialismo con la mística judía, van a ser el objeto explícito del trabajo Sobre el concepto de historia y serán tratados en su momento, por lo que por ahora es preciso acotar las referencias al materialismo histórico a lo que se expone en el Libro de los pasajes, de donde se recuperan cuatro aspectos metodológicos centrales: Primero: una inextricable articulación teórico-metodológica del materialismo histórico con la dialéctica, especialmente en el sentido destructivo o crítico de ésta; segundo: la exposición problemática de la elusiva "imagen dialéctica” y su concreción monadológica (montaje/constelación) como expresión adecuada al saber proveído por el materialismo histórico; tercero: la reivindicación de lo discontinuo, lo pequeño, lo cotidiano, lo ruinoso y en apariencia muerto como "objeto histórico" y el papel que en ello cumple el historiador materialista en calidad de "coleccionista" o de "trapero"; y, cuarto: el destacable y cada vez más radical carácter político y revolucionario que anima el esfuerzo crítico de Benjamin. ${ }^{5}$

\footnotetext{
4 Sin cursivas en el original. Nota del autor.

5 Ver: Benjamin, W. (2005). Especialmente los Convolutos J [Baudelaire], N [Teoría del conocimiento, teoría del progreso], U [Saint-Simón, ferrocarriles], W [Fourier] y X [Marx].
} 
Todo ello, sin embargo, encuentra en el trabajo Sobre el concepto de historia (2005a) su examen y desarrollo más completos; lo que en Benjamin significa el enriquecimiento de una agenda de trabajo "por hacer" y no el de una obra terminada, aun cuando, en calidad de esbozo, en el texto que también se conoce como Tesis sobre el concepto de historia, resume esencialmente su concepto de materialismo histórico, presenta un apretado apunte sobre los principales activos analíticos y expositivos con los que éste cuenta y establece los anclajes de la liga teórico-metodológica con su propia versión y aplicaciones de la mística judía. En sustancia, Benjamín afirma que el materialismo histórico, siempre en ceñida articulación con la dialéctica, conserva formalmente la posibilidad de aprehender y explicar los elementos esenciales del acaecer y, especialmente, de la lucha contra el fascismo. Sin embargo, considera que la forma dominante del materialismo histórico es en esos momentos, - sobre todo en sus versiones socialdemócrata y marxista-leninista-, sostenida por posiciones que conservan un alto índice de positividad, lo que les impide discernir definitivamente "lo verdadero de lo falso" y, por tanto, permanecen inhabilitadas para reivindicar como elemento imprescindible del conocimiento histórico tanto el sufrimiento de las generaciones de vencidos como la acción combatiente y revolucionaria del proletariado.

\begin{abstract}
El sujeto del conocimiento histórico es la clase oprimida misma cuando combate. En Marx aparece como la última clase esclavizada. Como la clase vengadora, que lleva a su fin la obra de liberación en nombre de tantas generaciones de vencidos. Esta conciencia, que por corto tiempo volvió a tener vigencia con el movimiento "Spartacus", ha sido siempre desagradable para la socialdemocracia. En el curso de treinta años ha logrado borrar casi por completo el nombre de un Blanqui, cuyo timbre metálico hizo temblar el siglo pasado. Se ha contentado con asignar a la clase trabajadora el papel de redentora de las generaciones futuras, cortando así el nervio de su mejor fuerza. En esta escuela, la clase desaprendió lo mismo el odio que la voluntad de sacrificio. Pues ambos se nutren de la imagen de los antepasados esclavizados y no del ideal de los descendientes liberados. (Benjamin, 2005(a), p. 25s)
\end{abstract}

En esta tesis - número XII en la versión de Bolívar Echeverría-, es posible reconocer las determinantes básicas del materialismo histórico de Benjamin y su idea de revolución. Las alusiones al movimiento comunista liderado por Rosa Luxemburgo y Karl Liebneck - llamado justamente Spartacus, y derrotado violentamente en enero de 1919- como su referencia a August Blanqui, el irreductible communard francés, son una muestra de simpatía hacia los procesos revolucionarios radicales en los que la "clase oprimida" asume el papel protagónico, a la vez que representan un deslinde definitivo respecto a la socialdemocracia, a la que por otra parte critica duramente en el conjunto de las Tesis. Sin embargo, el punto fuerte lo representa la crítica a lo que nuestro autor llama "índice de positividad", cultivado habitualmente por el positivismo y el historicismo - aunque escandalosamente obtuso y claudicante en el materialismo vulgar de la socialdemocracia alemana-, que a su vez se funda en un concepto acrítico e irreflexivo de progreso.

La idea de un progreso del género humano en la historia es inseparable de la representación de un movimiento como un avanzar por un tiempo homogéneo y vacío. La crítica de esta representación del movimiento histórico debe constituir el fundamento de la crítica de la idea de progreso en general. (Benjamin, 2005(a), p. 27)

Mas, el concepto de progreso es igualmente solidario con la idea de un tiempo "homogéneo y vacío" y una concepción de la historia que la presenta como proceso de desarrollo o evolución continua; idea -adoptada tanto por la socialdemocracia como por el tipo de materialismo evolutivo que sostiene el marxismo soviético-, que ha llevado a la clase obrera a la corrupción y al conformismo. (Benjamin, 2005(a), p. 24).

El conformismo, que desde el principio se encontró a gusto en la socialdemocracia, no afecta sólo a sus tácticas políticas, sino también a sus ideas económicas. No hay otra cosa que haya corrom- 
pido más a la clase trabajadora alemana que la idea de que ella nada con la corriente. El desarrollo técnico era para ella el declive de la corriente con la que creía estar nadando. De allí no había más que un paso a la ilusión de que el trabajo en las fábricas, que sería propio de la marcha del progreso técnico, constituye de por sí una acción política. Bajo una figura secularizada, la antigua moral protestante del trabajo celebraba su resurrección entre los obreros alemanes. (Ídem)

Ahora, desmontar críticamente el dispositivo conceptual sobre el que se sostiene la idea de progreso $-y$ junto con ella todos los vicios historiográficos y políticos que se le asocian-, obliga a Benjamin a repensar la función que la concepción del tiempo cumple tanto en el nivel epistemológico de la relación sujeto-objeto como en la construcción historiográfica de un objeto histórico cuya construcción no se efectúe en el "vacío" y, a la vez, eluda la positividad apologética que espontáneamente porta el relato de los vencedores, cuyo ejemplo y summa es la llamada Historia Universal. (Benjamin, 2005(a), p. 29). Aquí, de cara a la necesidad de conjugar en una constelación crítica el dominio de unos y el sufrimiento de otros, recuperar una original idea del tiempo y proponer un renovado y radical concepto de revolución, es justamente el enclave teórico en donde se opera la extraña, pero sugerente, inclusión de algunos aspectos de la mística judía en la concepción benjaminiana de la historia y en su propuesta de renovación crítica del materialismo histórico.

Tanto en la figura del "enano jorobado" (Benjamin, 2005(a), p. 17), que siempre hará vencer al materialismo histórico en cuanto éste expulse de sí la consideración de una historia continua y progresiva e incorpore a su instrumental crítico-dialéctico algunos elementos de "la teología" capaces de revelar lo que el pasado porta de "tradición", de "redención" de "débil fuerza mesiánica" y de "promesa de felicidad", como en las ideas de un "tiempo-del-ahora" (Benjamin, 2005(a), p. 27) "detención mesiánica del acaecer" (Benjamin, 2005(a), p. 29) y aun de apokatastasis (Benjamin, 2005, p. 461-462), es indiscutible que Benjamin se remite al discurso tradicional judío su versión mesiánica.

Pero es igualmente indiscutible que, por ello mismo, en lugar de demeritar la tradición marxista, de algún modo la enriquece y actualiza, en tanto son esos elementos aparentemente "extraños" al materialismo histórico los que en su tiempo le permitirán al crítico alemán emplazar la "lucha contra el fascismo" y, con la misma fuerza y pertinencia, los que, en la actualidad, han permitido a las y los críticos más lúcidos de la modernidad capitalista, incorporar en sus consideraciones y argumentos el carácter "mesiánico" y el "tiempo-del-ahora" con el que a lo largo de siglos transcurrieron, y aún transcurren - siempre de conformidad con sus propias tradiciones y su modelos de resistencia-, los movimientos y luchas de nuestros pueblos originarios. ${ }^{6}$ Aunque eso, para Benjamin - y para aquellas autoras y autores de las que se habla-, no es suficiente.

Por una parte, es preciso recuperar ese pasado como un "momento de peligro", rechazar el conformismo en todas sus variantes y reconocer, sin ambigüedad, al enemigo:

Articular históricamente el pasado no significa conocerlo "como verdaderamente fue". Significa apoderarse de un recuerdo tal como éste relumbra en un momento de peligro [...] El peligro amenaza tanto a la permanencia de la tradición como a los receptores de la misma. Para ambos es uno y el mismo: el peligro de entregarse como instrumentos de la clase dominante. En cada época es preciso hacer nuevamente el intento de arrancar la tradición de manos del conformismo, que siempre está a punto de someterla. Pues el Mesías no solo viene como Redentor, sino también como vencedor del Anti-Cristo. Encender en el pasado la chispa de la esperanza es un don que sólo encuentra aquel historiador que está compenetrado con esto: tampoco los muertos estarán a salvo del enemigo, si este vence. Y este enemigo no ha dejado de vencer. (Benjamin, 2005(a), p. 20).

Pero, por otra parte, porque es igualmente necesario asumir que el instante revolucionario es una "interrupción mesiánica del acaecer" que no produce una nueva "situación histórica", sino una nueva tarea

$6 \quad$ Ver: Gutiérrez, R. (2008). 
revolucionaria. Y esto es lo que se precisa subrayar justo ahora, no sólo cuando vivimos un continuo y furioso "momento de peligro", sino cuando menos claras aparecen las oportunidades para la transformación revolucionaria del mundo o, finalmente, cuando en favor de una visión conservadora del marxismo, nos cegamos ante el evidente potencial revolucionario del "mesianismo" y del "pesimismo activo".

En realidad, no hay un instante que no traiga consigo su oportunidad revolucionaria [...]. Al pensador revolucionario, la oportunidad revolucionaria peculiar de cada instante histórico se le conforma a parir de una situación política dada. Pero se le confirma también, y no en menor medida, por la clave que dota a ese instante del poder para abrir un determinado recinto del pasado, completamente clausurado hasta entonces. El ingreso en ese recinto coincide estrictamente con la acción política; y es a través de él que ésta, por aniquiladora que sea, se da a conocer como mesiánica. (Benjamin, 2005(a), p. 30).

El concepto - o idea-imagen de revolución de Walter Benjamin, como preferimos considerarlo- conserva en principio el sentido y el radicalismo que la Modernidad ha inscrito en él y que ésta reconoce en todos y cada uno de sus "momentos fundantes": una ruptura radical del "orden establecido" que provoca transformaciones más o menos violentas y profundas en el conjunto de la vida social o en alguna de sus esferas específicas: la política, la economía, las ciencias y las artes, el entretenimiento y la vida cotidiana. A esa idea tradicional de revolución debemos agregar, propuestos por Benjamin, dos usos distintivos. El primero alude al hecho de que en la mayoría de los casos el término se aplica con un agudo sentido crítico; el segundo afirma que a pesar de conservar lo esencial de la concepción moderna de revolución, el sentido que sobre todo el último Benjamin inscribe en ésta, lo sitúa en un horizonte masivamente transgresor, en el que se efectúa una "revolución en el concepto de revolución".

Aun cuando ya en sus trabajos juveniles puede reconocerse el esbozo de lo que con el tiempo va a llegar a ser su concepción definitiva, probablemente la primera manifestación explícita de este uso crítico del concepto de revolución se encuentra en el trabajo de 1921 Para una crítica de la violencia, en donde, después de examinar las limitaciones doctrinarias de las escuelas de interpretación iusnaturalista y positivista del derecho, la primera conclusión crítica a la que arriba Benjamin es que el derecho y la justicia son antónimos: donde hay derecho hay estado, pero no hay justicia. "La función de la violencia - escribe Benjamin - por la cual ésta es tan temida y aparece, con razón, para el derecho como tan peligrosa, se presentará justamente allí donde todavía le es permitido manifestarse según el ordenamiento jurídico actual" (Eagleton, 1998, p. 196) $7^{*}$ De modo que la justicia, si es verdaderamente aquello por la que preguntamos, es una categoría propia de las sociedades sin estado; sea las que florecieron en el curso de la infancia de la humanidad y que, por ello mismo decía Cervantes por boca de Don Quijote, recibieron el nombre de Edad de oro, o la que, como fin puro de la revolución, será la sociedad sin clases. En estos señalamientos podemos encontrar el núcleo de la crítica radical del concepto moderno de revolución, el que, sea cual sea su vía de realización: la conquista, el contrato o una guerra de liberación, siempre se resolverá como en un nuevo y cíclico "estado de derecho", es decir, un estado de cosas en el que impera un nuevo tipo de orden, pero en el que no impera la justicia, porque la justicia únicamente será efecto de una conmoción social o de un tipo de violencia que no "funda el derecho" ni "conserva el derecho", sino establece la justicia plena o el verdadero "reino de los fines". Benjamin no desarrolla expresamente la formula "reino de los fines", que proviene de Kant; sin embargo, dado que la discusión en torno a las posiciones iusnaturalista y positivista respecto a los fines naturales y los fines jurídicos o los medios sin más y los medios puros, se dirime exclusivamente en el "reino de los medios", su denuncia se dirige justamente a la ausencia, en aquella, de las determinantes transgresoras del "reino de los fines". Sobre todo en lo que respecta al derecho, es evidente para nuestro autor que la relación fundamental y más elemental de todo ordenamiento jurídico es la de fin y medio: y que la violencia, bajo los parámetros de la tradición jurídica, sólo puede ser discutida en el reino de los medios y no en el de los fines.

Benjamin asocia cierto tipo de violencia o conmoción social a una clase de medios históricos cuya mar-

$\overline{7 \quad \text { * Benjamin citado por Eagleton. }}$ 
cada condición alegórica hace un tanto oscuro su sentido. Siguiendo a Georges Sorel (1976), el pesador anarquista francés, postula la "huelga general revolucionaria" (en ocasiones la llama "huelga general proletaria" en oposición a la "huelga general política") como un medio puro, no violento, pero enfáticamente revolucionario, para alcanzar la justicia en una futura sociedad sin clases: "Por cuanto respecta a las luchas de clase, bajo ciertas condiciones hay que considerar sin duda la huelga como medio puro" (Eagleton, 1998, p. 196). Un medio revolucionario puro, de acuerdo con Benjamin, genera una empresa "anárquica" en donde la revolución se presenta bajo la forma inmediata de una concepción moral que se plantea como objetivo la destrucción del poder del estado; no para reconstruir otro, sino para establecer las condiciones de existencia de una sociedad sin estado.

\begin{abstract}
Mientras que la primera forma de suspensión del trabajo (la huelga general política) es ya violencia, por cuanto causa solamente una exterior modificación de las condiciones de trabajo, la segunda (la "huelga general proletaria") carece de violencia, es decir, es un medio puro. Pues esta no se da con la intención de reanudar el trabajo nuevamente tras obtener concesiones exteriores junto a concretas modificaciones de las condiciones de trabajo, sino con la decisión de reanudar un trabajo completamente transformado; uno no forzado por el Estado (un cambio radical que este tipo de huelga no provoca, sino que sólo consuma).(Eagleton, 1998, p. 197)
\end{abstract}

El autor procura establecer un contraste nítido entre aquella forma de violencia que produce horror y sangre y cuyos motivos se asocian principalmente a la venganza y la fundación y conservación del poder - a la que da el nombre de violencia mítica - y una forma de violencia, propiamente fulmínea, dice, que ni crea el derecho ni conserva el derecho, sino que abre la puerta a lo que llama la "conversación"; esto es, la fundación no violenta de una verdadera comunidad humana. De esa manera, esta forma de la revolución, representada en Hacia una crítica de la violencia con la figura alegórica de la "violencia divina", tiene la virtud de romper el círculo cerrado de las revoluciones "históricas" que en su momento han destruido una forma "arcaica" o "superada" del derecho solamente para fundar un nuevo derecho destinado, a su vez, a su desgaste y decadencia. Bajo esta última figura, es decir, la "interrupción" del ciclo histórico, se esboza ya un nuevo concepto de revolución en donde a un acto destructivo no sigue un acto constructivo, sino una “nueva época histórica”. (Eagleton, p. 205)

Casi veinte años más tarde, es en el trabajo Tesis sobre el concepto de historia (2005a) el ámbito en el que Benjamin concreta su propio concepto de revolución, el que adquiere su sentido pleno en aguda oposición dialéctica con los conceptos de revolución propios de la Modernidad y del materialismo vulgar, de manera que no le es posible abordarlo y expresarlo sino a través de su articulación/oposición negativa con aquellos. Ello implica, en primer término, romper el círculo vicioso en el que en el marco del historicismo se conciben las revoluciones, el que opone mecánicamente lo "viejo" - representado alternativamente por el "estado de naturaleza", el "antiguo régimen" o el "dominio colonial" - a lo presumiblemente "nuevo"; lo que siempre se presenta como resultado de un hecho de conquista, un pacto social o un proceso de independencia nacional. En consecuencia, se hace preciso someter a crítica y finalmente romper con los conceptos moderno-burgués y materialista vulgar de historia y progreso. Este proceso, por una parte, representa una empresa de deducción crítico-categorial de claro perfil histórico-filosófico en el que Benjamin es proveído teóricamente por las herramientas propias del materialismo histórico; pero, por otra, abre y desplaza el horizonte de la discusión hacia un ámbito de orden "teológico", específicamente mesiánico. Para evitar discusiones inútiles es preciso adelantar aquí la conclusión de que para Benjamin lo mesiánico no es sinónimo de, ni se reduce a, lo "teológico", sino alude a lo específicamente revolucionario; mientras la revolución es el objetivo y fin de toda redención mesiánica (Löwy, p. 2001, 69-70); sin que ello implique en ningún momento el abandono del materialismo histórico, sino el emplazamiento de una heterodoxa y audaz reinterpretación del mismo.

Desde el momento en el que la Modernidad se hizo cargo de recuperar y expresar su propio proceso de realización histórica, le ha dado a su concepto de revolución un sentido eminentemente histórico-filosófico y, en correspondencia, ha privilegiado sus aplicaciones histórico-narrativas, sobre todo cuando éstas 
se refieren a eventos de orden político-jurídico cuya sucesión temporal dará algún día con la fórmula de la "paz perpetua". ${ }^{8}$ En ese marco conceptual, dicho concepto de revolución es absolutamente solidario con el igualmente moderno concepto de progreso, ya que la Modernidad entiende como tal el continuo perfeccionamiento de las instituciones en las que "lo nuevo" cobra cuerpo. Esta sucesión implica concebir lo histórico como una cadena de eventos que se desplazan en una "flecha del tiempo" que se dirige siempre hacia el futuro bajo la forma de un continuum y en un espacio homogéneo y vacío. (Eagleton, 1998, p. 314). En éste, las revoluciones son eventos que pueden llegar a conmocionar profundamente ciertos estados de cosas, pero, finalmente, no son sino un "momento" de la incesante marcha de la humanidad. Esa idea afirmativa de revolución es la que empata plenamente con las posturas historicista, positivista y materialista vulgar y con su concepción progresiva, evolucionista y mecánica de la historia, a la que Benjamin dirige su más aguda crítica por ser, justamente, la que ha dado al traste con la idea de revolución en el pensamiento propio del reformismo y la socialdemocracia.

\begin{abstract}
La teoría socialdemócrata, y aún más su práctica, estuvo determinada por un concepto de progreso que no se atenía a la realidad, sino que poseía una pretensión dogmática. Tal como se pintaba en la cabeza de los socialdemócratas, el progreso era, primero, un progreso de la humanidad misma (y no sólo de sus destrezas y conocimientos). Segundo, era un progreso sin término (en correspondencia con una perfectibilidad infinita de la humanidad). Tercero, pasaba por esencialmente indetenible (recorriendo automáticamente un curso recto o en espiral). Cada uno de estos predicados es controvertible y en cada uno de ellos la crítica podría iniciar su trabajo. Pero la crítica -si ha de ser inclemente- debe ir más allá de estos predicados y dirigirse a algo que les sea común a todos ellos. (Benjamin, 2005(a), p. 26-27)
\end{abstract}

En contraste, para Benjamin, los conceptos de historia y revolución no son positivos, sino críticos. Nombran una conmoción social de índole totalizante y radical que interrumpe el curso continuo de la historia; no sitúa la lucha revolucionaria en un tiempo "fuera del tiempo" sino en un pleno y radical "tiempo-del-ahora" que finalmente no representa la redención de "nuestros nietos" en el futuro, sino de "los vencidos" en el pasado. Esto es posible porque Benjamin concibe todo el pasado histórico de la humanidad como un feroz y violento "huracán", una catástrofe cuyo desarrollo continuo no ha dejado de "acumular escombros" (Benjamin, 2005p. 23), cuya superación implica un radical esfuerzo de rememoración/acción revolucionaria. ¿Cómo frenar ese huracán?, ¿cómo hacer frente a esa catástrofe? "Marx dice que las revoluciones son las locomotoras de la historia mundial. Pero tal vez se trata de algo completamente diferente. Tal vez las revoluciones son el manotazo hacia el freno de emergencia que da el género humano que viaja en ese tren" (Benjamin, 2005, p. 37).

Caracterizado el ejercicio del dominio burgués como una verdadera "máquina loca" — pero metaforizada en el huracán que aterroriza al Ángel de la Historia y que no deja de arrojar escombros a sus pies-, de no oponérsele la revolución, de no ser interrumpida su cauda destructiva, de no aplicársele con la urgencia del caso el freno de emergencia, la historia-progreso conducirá a la humanidad a su inminente destrucción. Es a partir de este señalamiento que podemos entender la frase alusiva al "freno de emergencia" de una manera alterna a la habitual y reconocer en ella mucho más fondo que una crítica simple al entusiasmo fáustico de Marx. Porque de lo que en realidad se trata es de un nuevo concepto crítico de revolución al que se asocia el conjunto de alegorías que, bajo la figura sintética de la "interrupción mesiánica del acaecer" (Benjamin, 2005(a), p. 29), caracterizan al hecho revolucionario como una ruptura que en su incurable inquietud y, bajo la fuerza iluminadora de un relámpago, también es capaz de reconocer la memoria perdida de los vencidos y la esperanza de los que no tienen esperanza. "La conciencia de hacer saltar el continuum de la historia es propia de las clases revolucionarias en el instante de su acción” (Benjamin, 2005, p. 27).

\footnotetext{
8 La noción kantiana de paz perpetua ilustra de manera emblemática la idea moderna y profana de progreso, en tanto hipotética culminación de la larga marcha de la humanidad en la realización de la finalidad que la naturaleza ha fijado para ella. Ver. Kant, I. La paz perpetua.

$9 \quad$ Entre los ferrocarrileros una "máquina loca" es aquella que, por alguna causa de entre las muchas que en los patios de maniobra pueden salirse de control, se desplaza sobre las vías ajena a toda posibilidad de manejo eficiente por parte del maquinista o de quienes se atrevan a tratar de frenarla, causando finalmente grandes y graves destrozos materiales y aun amenazando seriamente la vida de los operarios. En la mayoría de los casos, tal "locura" se manifiesta en ausencia del maquinista o a causa de ésta.
} 
Este salto, empero, como efecto de una “interrupción mesiánica” del proceso histórico, es la única y quizá última posibilidad de poner fin a la catástrofe y preparar el advenimiento de una sociedad sin clases. Qué significa aquella "interrupción mesiánica" es materia de interminables discusiones; sin embargo, intentar comprenderlas implica asumir que "como escritor judío, Benjamin era un hereje" (Buck-Morss, 2001, p. 262), y que el mesianismo al que se asocia su concepto de revolución es completamente compatible con los postulados originales de Marx y del materialismo histórico-dialéctico.

\section{REFERENCIAS}

Benjamin, W. (1981). Baudelaire. En, T. Eagelton. W. Benjamin. O hacia una crítica revolucionaria. Cátedra.

Benjamin, W. (2005). Libro de los pasajes. Akal.

Benjamin, W. (2005a). Tesis sobre el concepto de historia. Contrahistorias.

Benjamin, W. (2007). El origen del Trauespiel alemán. En W. Benjamin. Obras, (pp. 217-459) Abada Editores.

Benjamin, W. (2009). Ensayos estéticos y literarios (Cont.) Obras, Libro II/Volumen 2. Abada

Buck-Morss, S. (1981). Origen de la dialéctica negativa, Theodor Adorno, Walter Benjamin y el Instituto de Frankfurt. Siglo XXI.

Buck-Morss, S. (1995). Dialéctica de la mirada. Walter Benjamin y el proyecto de los pasajes. La balsa de Medusa.

Cohen, E. (Edit.). (2016). Glosario Walter Benjamin. UNAM.

Eagleton, T. (1998). Walter Benjamin o hacia una crítica revolucionaria. Cátedra.

Forster, R. (2014). La travesía del abismo. Mal y Modernidad en Walter Benjamin. Fondo de Cultura Económica.

Gutiérrez, R. (2008). Los ritmos del Pachakuti Movilización y levantamiento popular-indígena en Bolivia (2000-2005). Tinta Limón.

Kant, I. (1999). La paz perpetua. (1795). Porrúa.

Löwy, M. (2020). El marxismo romántico de Walter Benjamin. Bajo el volcán. Revista del Posgrado de Sociología. 8, 85-100. http://www.apps.buap.mx/ojs3/index.php/bevol/article/view/1672

Löwy, M. (2001). Walter Benjamin. Aviso de Incendio. Fondo de Cultura Económica.

Lukács, G. (1985). Metafísica de la tragedia en El alma y las formas. Grijalbo.

Muschg, W. (1965). Historia trágica de la literatura. Fondo de Cultura Económica.

Scholem, G. (1987). Walter Benjamin, Historia de una amistad. Península.

Sorel, G. (1976). Reflexiones sobre la violencia. Alianza.

Tiedemann, R. (2005). Introducción. En, W. Benjamin. Libro de los Pasajes. Akal.

\section{AUTOR}

Aureliano Ortega Esquivel. Doctor en filosofía por la UNAM. Líneas de Investigación: Filosofía de la Historia y de las Teorías Sociales; Teoría crítica. Miembro del SNI-Conacyt. Nivel III.

\section{Conflicto de intereses}

El autor informa que no existe ningún conflicto de interés posible.

Financiamiento

No existió asistencia financiera de partes externas al presente artículo.

Agradecimientos

$\mathrm{N} / \mathrm{A}$

Sobre el artículo

El artículo que se presenta es producto de su actual proyecto de investigación y se enmarca en la línea de Teoría crítica. 